tháng 7/2018 cho thây việc sử dung phác đồ giải độc bằng ethanol đường uống là có hiệu quả. Nồng độ ethanol máu tăng dần, đạt được nồng độ mục tiêu sau 3,4 $\pm 2,36$ giờ, duy trì được cho đến khi hết chỉ định dùng ethanol. Kết quả điều trị có $45,9 \%$ sống không có di chứng, $21,3 \%$ có di chứng và 20 bệnh nhân tử vong chiếm tỉ lệ $32,8 \%$. Thời gian điều trị ethanol đường uống là $8,2 \pm 2,17$ giờ. Thời gian nằm viện trung bình là 4 ngày.

TÀI LIỆ THAM KHẢO

1. Zakhazov $S$, et al. (2015). Fluctuations in serum ethanol concentration in the treatment of acute methanol poisoning: a prospective study of 21 patients. Biomed Pap Med Fac Univ Palacky Olomouc Czech Repub, 159

2. Phạm Như Quỳnh, Lê Đình Tùng, Hà Trân Hứng (2017). Hiểu quả của thẩm tách máu kéo dài trong điều trị bểnh nhân ngộ độc cấp methanol. Tap chí Sinh lý hoc Viêt Nam, 21(3), 13-20.

3. Nguyến Đàm Chính, Hà Trân Hưng (2016). Nhận xét kết quả điều trị bệnh nhân ngộ độc câp methanol taai Trung tâm chống độc bệnh viện Bạch Mai.Tap chí nghiên cứu y hoc,440(1),29-33

4. McMartin K, Jacobsen D, Hovda K.E. (2015). Antidotes for poisoning by alcohols that form toxic metabolites, British Journal of Clinical Pharmacology.

5. Girault C, et al, (1999). Fomepizole (4methylpyrazole) in fatal methanol poisoning with early CT scan cerebral lesions. J Toxicol Clin Toxicol, 37(6), 777-80.

6. Rietjens S.J, D.W. de Lange, and J. Meulenbelt(2014). Ethylene glycol or methanol intoxication: which antidote should be used, fomepizole or ethanol? Neth J Med, 2014. 72(2), 73-9.

7. Barceloux D.G, et al. (2002). American Academy of Clinical Toxicology practice guidelines on the treatment of methanol poisoning. J Toxicol Clin Toxicol, 40(4), 415-46

8. Lee C.Y, et al, (2014). Risk factors for mortality in Asian Taiwanese patients with methanol poisoning. Ther Clin Risk Manag, 10, 61-7.

9. Wedge M.K, et al. (2012). The safety of ethanol infusions for the treatment of methanol or ethylene glycol intoxication: an observational study, Canadian Association of Emergency Physicians CJEM, 14(5), 283-289.

\title{
MộT Số YẾU Tố LIÊN QUAN ĐẾN CHİ Số HUYẾT ÁP TÂM THU Cổ CHÂN - CÁNH TAY Ở BỆNH NHÂN BỊ BỆNH ĐộNG MACH CHI DƯớI
}

\section{TÓM TẮT}

Hoàn cảnh nghiên cứu: Phương pháp đo chỉ số huyết áp tâm thu cổ chân cánh tay (ABI) với phương tiện và kỹ thuật đơn giản, được khuyến cáo trong sàng lọc và chẩn đoán bênh đông mach chi dưới. Các nghiên cứu trên thế giới cho thấy $A B I$ không những có độ nhạy và độ đặc hiệu cao mà chỉ số này còn tương quan chặt chẽ̃ với mức độ nặng của BĐMCD. Phương pháp nghiên cứu: Là nghiên cứu mô tả cắt ngang trên 158 chi dưới ở 79 bênh nhân bị BĐMCD. Bênh nhân được chụp MSCT động mạch chi dưới, khám lâm sàng và đo chỉ số $A B I$. Sau đó tìm mối liên quan giữa chỉ số $A B I$ với các đăc điểm lâm sàng và tổn thương động mạch chi dưới trên phim chụp MSCT. Kết quả: Trị số $A B I$ thấp hơn có ý nghĩa ở nhóm chi tổn thương từ hai đônng mach trở lên so với nhóm chỉ có tổn thương một động mạch $(p=0,002)$; ở nhóm chi tổn thương từ hai tâng mạch trở lên so với nhóm chỉ có tổn thương một tầng mach $(p=0,01)$; và ở nhóm chi có tắc hoàn toàn lòng động mạch so với nhóm chỉ có hẹp lòng động mạch $(p<0,001)$. Trị số $A B I$ cũng thấp

\section{*Đại Học Y Dược Thái Binh \\ ** Dai Hoc Y Hà Nôi}

Chiu trách nhiệm chính: Trần Xuân Thủy

Email: bsxuanthuyytb@gmail.com

Ngày nhận bài: 4.01.2021

Ngày phản biên khoa học: 26.2.2021

Ngày duyệt bài: 4.3.2021

\section{Trần Xuân Thủy*, Đinh Thị Thu Hương**}

hơn có ý nghĩa ở nhóm chi triệu chứng đau so với nhóm chi không đau $(p=0,001)$; ở nhóm chi có triệu chứng thiếu máu trầm trong so với nhóm chi không có triệu chứng này $(p=0,001)$. Kết luận: Chỉ số $A B I$ tương quan có ý nghĩa với mức độ lâm sàng và mức độ tổn thương động mạch khi đối chiếu với chụp MSCT đông mach chi dưới.

Từ khóa: Bệnh động mạch chi dưới, Chỉ số $A B I$, Chup MSCT.

\section{SUMMARY}

\section{SOME RELATED FACTORS TO ANKLE - BRANCHIAL INDEX (ABI) IN PATIENT WITH LOWER EXTREMITY ARTERY DISEASE}

Background: The ankle - branchial index (ABI) is simple to performed, so it is recommended to screen and early diagnose the lower extremity artery disease (PAD). Beside the high sensitivity and the high speccificity, rearches in the world has shown that ABI have close relationship to the severity of PAD. Subjects and Methods: A Cross-sectional study on 158 lower limbs of 79 patients with lower extremity artery disease. Patients were performed lower lim artery MSCT, took medical history, clinical examined and measured ABI. Then, we finded the relationship of $A B I$ to clinical characteristics and subcliniccal characteristics on MSCT. Results: ABI was significantly lower in the limbs with $\geq 2$ sick arteries in compare to limbs with one sick artery $(p=0,002)$, in the limbs with $\geq 2$ sick artery floors in compare to 
limbs with one sick artery floor $(p=0,01)$. ABI was also significantly lower in the limbs with pain in compare to limbs without pain $(p=0,001)$; and the limbs with symptom of severe anemia in compare to limbs without this symptom ( $p=0,001)$. Conclusions: The ankle - branchial index had a significantly corelation to the severity of clinical symptom of the lower extremity artery disease and the level of artery damage on MSCT.

\section{I. ĐĂT VẤN ĐỀ}

Bệnh động mạch chi dưới (BĐMCD) là bệnh lý xơ vữa các động mạch cấp máu cho chi dưới và các nhánh chính của nó dẫn đến giảm lượng máu tới các mô mà động mạch chi phối [1]

Mặc dù tỷ lệ bệnh tại cộng đồng cao và đang gia tắng nhanh [2], song BĐMCD dễ bị bỏ sót do bệnh tiến triển âm thầm và ít triệu chứng. Tại thời điểm chẩn đoán có khoảng $50 \%$ bênh nhân không có triệu chứng [3], vì vậy cần có phương pháp chẩn đoán bệnh sớm để điều trị bệnh kịp thời.

Phương pháp chụp MSCT có độ chính xác cao ngang bằng với phương pháp chụp động mạch xâm lấn và đang trở thành tiêu chuẩn vàng chẩn đoán $\mathrm{BĐMCD}[4]$, Tuy nhiên, do phương tiện và kỹ thuật phức tạp nên phương pháp này không thích hợp để sàng lọc bệnh.

Chỉ số huyết áp tâm thu cổ chân cánh tay (ABI) là tỷ lệ giữa huyết áp tâm thu đo ở chi dưới (ĐM mu chân hoặc ĐM chày sau) với huyết áp tâm thu cánh tay. Hiện nay phương tiện đo ABI rất nhỏ gọn, kỹ thuật đơn giản, có độ nhạy và độ đặc hiệu cao[5], do đó rất thích hợp để sàng lọc và chẩn đoán $B \boxminus M C D$. Các nghiên cứu trên thế giới cũng cho thấy bên cạnh giá trị chẩn đoán cao, chỉ số $A B I$ còn có tương quan chặt chẽ với độ nặng và là yếu tố tiên lượng của $\mathrm{BĐMCD}[6][7]$.

Xuất phát từ vấn đề này chúng tôi tiến hành nghiên cứu với mục tiêu sau: Tìm hiểu một số liên quan đến chỉ số $A B I$ ở bệnh nhân bị bệnh động mạch chi dưới có đối chiếu với phương pháp chụp MSCT.

\section{II. ĐỐI TƯỢNG VÀ PHƯƠNG PHÁP NGHIÊN CỨU}

\section{1. Địa điểm và thời gian nghiên cứu:}

Nghiên cứu được tiến hành tại Viện Tim Mạch Bệnh Viện Bạch Mai từ tháng 01/2013 đến tháng $12 / 2016$

2. Đối tượng nghiên cứu: 158 chi dưới ở 79 bệnh nhân được chẩn đoán BĐMCD tại Viện Tim Mạch - Bệnh viện Bạch Mai từ tháng 1/2013 đến tháng 12/2016.

Tiêu chuẩn lựa chọn bệnh nhân: Bênh nhân bị BĐMCD đã được chụp MSCT động mạch chi dưới đồng ý tham gia nghiên cứu

- Tiêu chuẩn loại trừ: Tổn thương động mạch chi dưới không do xơ vữa, đã bị cắt cụt chi không đo được $A B I$, hoặc không đồng ý tham gia nghiên cứu

3. Phương pháp nghiên cứu:

- Là nghiên cứu mô tả cắt ngang trên bệnh nhân bị BĐMCD.

Các bệnh nhân bị BĐMCD đã chụp MSCT đủ tiêu chuẩn lựa chọn vào nghiên cứu được khai thác bênh sử, thăm khám lâm sàng, đo chỉ số ABI. Sau đó tìm hiểu mối liên quan giữa chỉ số $A B I$ với một số yếu tố lâm sàng và tổn thương động mạch trên hình ảnh chụp MSCT động mạch chi dưới.

Xử lý số liệu: Phương pháp thống kê y học theo chương trình SPSS 16.0.

\section{KẾT QUẢ NGHIÊN CỨU}

Qua nghiên cứu 158 đoạn chi trên 79 bệnh nhân bị BĐMCD chúng tôi thu được kết quả sau:

1. Đặc điểm chung của nhóm nghiên cứu:

Bảng 1: Môt số đặc điểm của nhóm nghiên cứu.

\begin{tabular}{|c|c|c|}
\hline \multirow{2}{*}{$\begin{array}{l}\text { Đặc điểm } \\
\text { tuối, giới }\end{array}$} & $\begin{array}{c}\text { Tuối trung bình: } \\
X \pm S D\end{array}$ & $\begin{array}{c}70,6 \pm \\
10,8\end{array}$ \\
\hline & Tỷ lê nam/ nữ & $3,4 / 1$ \\
\hline \multirow{3}{*}{$\begin{array}{l}\text { Môtt số yếu } \\
\text { tố nguy cơ }\end{array}$} & Tỷ lệ hút thuốc lá & $40,5 \%$ \\
\hline & $\begin{array}{l}\text { Tỳ lệ đái tháo } \\
\text { đường }\end{array}$ & $25,3 \%$ \\
\hline & Tỷ lệ tăng huyết áp & $65,8 \%$ \\
\hline
\end{tabular}

Nhân xét: - Nam giới chiếm tỷ lệ cao, tỷ lệ nam/nữ $=3,4 / 1$.

- Tỷ lệ THA, ĐTĐ, hút thuốc lá là: 65,8\%; $25,3 \%$ và $40,5 \%$ tương ứng.

\section{2. Đặc điểm tổn thương động mạch trên chụp MSCT động mạch chi dưới} Bảng 2: Đặc điểm tổn thương động mạch

\begin{tabular}{|c|c|c|}
\hline \multirow{2}{*}{ Tỷ lệ chi dưới bị BĐMCD } & $87,3 \%(138 / 158)$ \\
\hline \multirow{2}{*}{$\begin{array}{c}\text { Đặc điểm phân bố số tầng } \\
\text { động mạch tổn thương }\end{array}$} & Tổn thương 1 tầng mạch & $25,4 \%(35 / 138)$ \\
\cline { 2 - 3 } & Tốn thương 2 tầng 7mạch & $28,2 \%(39 / 138)$ \\
\hline \multirow{2}{*}{$\begin{array}{c}\text { Đặc điểm phân bố số động } \\
\text { mạch tổn thương }\end{array}$} & Tốn thương 3 tầng mạch & $46,4 \%(64 / 138)$ \\
\cline { 2 - 3 } & Tô̂n thương 1 động mạch & $16,7 \%(23 / 138)$ \\
\cline { 2 - 3 } & Tốn thương 2 động mạch & $27,5 \%(38 / 138)$ \\
\hline
\end{tabular}


Đặc điểm phân bố theo

mức độ hẹp đường kính

lòng động mạch

\begin{tabular}{|c|c|}
\hline Hẹp nhẹ - vừa < 70\% đường kính lòng ĐM & $5,1 \%(7 / 138)$ \\
\hline Hẹp khít > 70\% đường kính lòng ĐM & $15,9 \%(22 / 138)$ \\
\hline Tắc hoàn toàn $\geq 1$ ĐM & $79 \%(109 / 138)$ \\
\hline
\end{tabular}

Nhận xét: Tỷ lệ chi dưới có tốn thương nhiều mạch máu, nhiêu tầng mạch và có tắc hoàn toàn ít nhất một động mạch chiếm tỷ lệ cao.

3. Đắc điểm triêu chứng lâm sàng ở nhóm chi bị bênh.

Bảng 3: Đặc điểm triệu chứng lâm sàng ở nhóm chi bị bệnh

\begin{tabular}{|c|c|c|c|c|}
\hline \multicolumn{3}{|r|}{ Triêuu chứng } & $\mathbf{n}$ & Tỉ lệ \% \\
\hline \multirow{3}{*}{$\begin{array}{c}\text { Triệu } \\
\text { chứng đau }\end{array}$} & \multicolumn{2}{|r|}{ Khồng có triệu chứng đau } & 46 & $33,3 \%$ \\
\hline & \multirow{3}{*}{$\begin{array}{c}\text { Có triêu } \\
\text { chứng đau }\end{array}$} & Đau cách hồi & 33 & $23,9 \%$ \\
\hline & & Triệu chứng thiếu máu chi mức độ trầm trọng & 59 & $42,8 \%$ \\
\hline \multirow{4}{*}{$\begin{array}{c}\text { Triệu } \\
\text { chứng bắt } \\
\text { mạch }\end{array}$} & & Tống số & 138 & $100 \%$ \\
\hline & \multicolumn{2}{|r|}{ Mạch bình thường } & 31 & $22,5 \%$ \\
\hline & \multirow{3}{*}{$\begin{array}{c}\text { Có triệu } \\
\text { chứng mạch }\end{array}$} & Mạch yếu & 19 & $13,8 \%$ \\
\hline & & Mất ít nhất một mạch & 88 & $63,7 \%$ \\
\hline & & Tống số & 138 & $100 \%$ \\
\hline
\end{tabular}

Nhận xét: Số chi có triệu chứng mức độ trầm trọng chiếm tỷ lệ cao (42,8 \%). Có 22,5 \% chi mạch bình thường; $13,8 \%$ chi dưới có mạch yếu. Số chi dưới không bắt được mạch chiếm $63,7 \%$.

4. Mối tương quan giữa chỉ số $A B I$ với mức độ tổn thương động mạch .

Bảng 4. Môi tương quan giữa chỉ số $A B I$ với mức độ tổn thường động mạch.

\begin{tabular}{|c|c|c|c|}
\hline \multicolumn{2}{|c|}{ Đặc điểm tổn thương động mạch } & ABI: $\quad X \pm S D$ & $\mathbf{p}$ \\
\hline \multirow{2}{*}{$\begin{array}{l}\text { Số tâng mạch } \\
\text { tổn thương }\end{array}$} & Một tầng mạch & $0,56 \pm 0,29$ & \multirow{2}{*}{0,01} \\
\hline & $\geq$ Hai tâng mạch & $0,41 \pm 0,34$ & \\
\hline \multirow{2}{*}{$\begin{array}{l}\text { Số mạch máu } \\
\text { tổn thương }\end{array}$} & Tổn thương một động mạch & $0,64 \pm 0,29$ & \multirow[b]{2}{*}{0,002} \\
\hline & Tốn thương $\geq$ hai động mạch & $0,41 \pm 0,32$ & \\
\hline \multirow{4}{*}{$\begin{array}{l}\text { Mức độ hẹp } \\
\text { mạch máu }\end{array}$} & Hẹp lòng động mạch & $0,68 \pm 0,30$ & \multirow{2}{*}{$<0,001$} \\
\hline & Tằc lòng động mạch & $0,38 \pm 0,31$ & \\
\hline & Hẹp nhẹ - vừa ( $\leq 70 \%$ đường kính ĐM) & $0,88 \pm 0,31$ & \multirow[b]{2}{*}{$<0,001$} \\
\hline & Hẹp khít - tắc (>70\% đường kính lòng ĐM) & $0,44 \pm 0,3$ & \\
\hline
\end{tabular}

Nhận xét: Trị số của chỉ số $A B I$ thấp hơn có ý nghĩa thống kê ở nhóm chi tổn thương nhiều mạch máu so với nhóm chi chỉ có tổn thương một mạch máu, ở nhóm chi tổn thương nhiều tânng mạch so với nhóm chi chỉ tổn thương 1 tầng mạch và ở nhóm chi có tắc động mạch so với nhóm chi chỉ có hẹp lòng động mạch.

5. Mối liên quan giữa chỉ số $A B I$ với biểu hiện lâm sàng ở chi dưới.

Bảng 5. Môi tương quan giứa chỉ số ABI với biểu hiện lâm sàng BĐMCD

\begin{tabular}{|c|c|c|}
\hline Đặc điểm lâm sàng & $\begin{array}{c}\text { ABI: } \\
X \pm S D\end{array}$ & $\mathbf{p}$ \\
\hline $\begin{array}{c}\text { Có triệu chứng đau } \\
\text { chi dưới }\end{array}$ & $0,38 \pm 0,31$ & \multirow{2}{*}{0,001} \\
\hline $\begin{array}{c}\text { Không có triệu chứng } \\
\text { đau chi dưới }\end{array}$ & $0,58 \pm 0,34$ & \\
\hline $\begin{array}{l}\text { Có triệu chứng thiếu } \\
\text { máu trầm trọng }\end{array}$ & $0,34 \pm 0,30$ & \multirow{2}{*}{0,001} \\
\hline $\begin{array}{l}\text { Không có triệu chứng } \\
\text { thiếu máu trầm trọng }\end{array}$ & $0,53 \pm 0,33$ & \\
\hline không mất mạch & $0,62 \pm 0,32$ & \multirow[b]{2}{*}{$<0,001$} \\
\hline $\begin{array}{c}\text { Có it nhât một mạch chi } \\
\text { dưới không bắt được }\end{array}$ & $0,35 \pm 0,30$ & \\
\hline
\end{tabular}

Nhận xét: Trị số ABI thấp hơn có ý nghĩa thống kê (với $p=0,001$ ):

- Ở nhóm có triệu chứng so với nhóm không có triêu chứng.

- Ở nhóm có biểu hiện thiếu máu trâm trọng so với nhóm không có biểu hiện thiếu máu trâm trọng.

\section{BÀN LUÂ̂N}

Chúng tôi nghiên cứu cắt ngang trên 158 đoạn chi ở 79 bệnh nhân, trong đó có 61 bệnh nhẩn nam và 18 bệnh nhân nữ; tỷ lệ nam/nữ $=$ $3,4 / 1$. Trong nghiên cứu Lê Văn Hùng thì tỷ lệ nam/nữ = 5,7/1[8].

Một số yếu tố nguy cơ: Trong nghiên cứu của chúng tôi, tỷ lệ bệnh nhân có hút thuốc, tăng huyết áp và đái tháo đường lần lượt là $40,5 \%$; $65,8 \%$ và $25,3 \%$ tương ứng. Nghiên cứu của Nguyễn Mạnh Hà cho thấy tỳ lệ bệnh nhân có hút thuốc trong quần thể nghiên cứu lên tới trên $60 \%$, tỷ lệ ĐTĐ là 26\%[9]. Theo Vũ Thúy Thanh thì tỳ lệ tăng huyết áp là $69 \%$.

Trong nghiên cứu của chúng tôi chỉ số $A B I$ có tương quan với mức độ tổn thương động mạch 
trên chụp MSCT. Trị số của ABI thấp hơn có ý nghĩa $(p<0,05)$ ở nhóm chi có tổn thương nhiều mạch, nhiều tầng và tắc lòng động mạch so với nhóm chỉ có tổn thương một động mạch, một tầng mạch và chỉ có hẹp động mạch đơn thuần.

Trị số của chỉ số $A B I$ cũng có tương quan với lâm sàng của BĐMCD. Trong đó $A B I$ có trị số thấp hơn có ý nghĩa ở nhóm chi có biểu hiện lâm sàng đau so với nhóm chi không có đau và ở nhóm chi có biểu hiện thiếu máu trầm trọng hơn so với nhóm chi không có biểu hiện thiếu máu trầm trong.

Tác giả Vũ Thúy Thanh tìm hiểu mối tương quan giữa giá trị $\mathrm{ABI}$ với mức độ tổn thương động mạch bằng việc lập phương trình tuyến tính thấy rằng: giá trị $A B I$ có tương quan nghịch với mức độ hẹp, số lượng động mạch chi dưới bị hẹp qua chụp MSCT với $r=-0,74 ; p<0,001$ và $r=-0,78 ; p<0,001$ tương ứng.

Theo Jelnes $\mathrm{R}$ thì giá trị $\mathrm{ABI}$ có tương quan chặt chẽ với độ nặng của $B Đ M C D$ và là yếu tố tiên lượng sống còn của chi. Giá trị $A B I$ càng thấp chứng tỏ bênh càng nặng. Nếu $A B I>0,5$ thì ít khả năng dẫn tới thiếu máu chi trầm trọng trong 6,5 năm tiếp theo[6]. Khi $A B I<0,4$ thì nguy cơ đau chi khi nghỉ, loét, hoại tử, khó lành vết thương và cắt cụt cao[7].

\section{KẾT LUẬN}

ABI tương quan có ý nghĩa với mức độ tổn thương động mạch chi dưới trên phim MSCT và mức độ lâm sàng của BĐMCD.

\section{TÀI LIẸU THAM KHẢO}

1. Hiatt W.R, Goldstone J, Smith $S$ et al (2008). Atherosclerotic Peripheral Vascular Disease Symposium II: nomenclature for vascular diseases. Circulation, 118(25), 2826-9.

2. Fowkes F.G, Rudan G, Rudan J et al (2013) Comparison of global estimates of prevalence and risk factors for peripheral artery disease in 2000 and 2010: a systematic review and analysis. Lancet, 382(9901), 1329-40.

3. Hirsch A. T, Criqui M. H et al (2001). Peripheral arterial disease detection, awareness, and treatment in primary care. Jama, 286(11), 1317-24.

4. Shareghi S, Gopal A et al (2010). Diagnostic accuracy of 64 multidetector computed tomographic angiography in peripheral vascular disease. Catheter Cardiovasc Interv, 75(1), 23-31.

5. Lijmer J. G, Hunink M. G et al (1996). ROC analysis of noninvasive tests for peripheral arterial disease. Ultrasound Med Biol, 22(4), 391-8.

6. Jelnes R GO, Hougaard Jensen K, và cs (1986). Fate in intermittent claudication: outcome and risk factors. Br Med J (Clin Res Ed), 293, 1137-1340.

7. Yao S.T (1970). Haemodynamic studies in peripheral arterial disease. Br J Surg, 57, 761 - 766.

8. Lê Văn Hùng 2001. "Nghiên cứu giá trị của siêu âm triplex đối chiếu với chụp mach trong chẩn đoán hẹp tắc động mạch chi dưới". Luận văn thạc sĩ y học.

9. Nguyến Mạnh Hà (2013). Nghiên cứu bệnh động mach chi dưới trên bệnh nhân có nguy cở cao tại Viển Tim Mạch Việt Nam. Luận văn thạc sỹ y học.

\section{MICROALBUMIN NIÊUU VÀ CÁC YẾU TỐ LIÊN QUAN Ở BÊ̂NH NHÂN ĐÁI THÁO ĐƯờ'NG TYP 2}

\section{TÓM TẮT}

Đái tháo đường là là bệnh lý thường gặp trong thực hành lâm sàng. Microalbumin niệu (MAÜ) là dấu ấn để phát hiếm sớm tổn thương thận ở bệnh nhân đái tháo đường. Mục tiêu nghiên cứu: Khảo sát microalbumin niệu và các yếu tố liên quan ở bệnh nhân đái tháo đường typ 2. Phương pháp nghiên cứu: Mô tả cắt ngang được thực hiện trên 60 bệnh nhân đái tháo đường typ 2. Kết quả: (1) MAU (+) xuất hiên ở 40 bênh nhân $(66,7 \%)$ trong số bênh nhân nghiên cứu; (2) MAU (+) ở bệnh nhân đái tháo

\footnotetext{
${ }^{1}$ Đai họ Y khoa Vinh

${ }^{2}$ Bệnh viện Hữu nghị đa khoa Nghệ An

Chịu trách nhiệm chính: Nguyễn Văn Tuấn

Email: tuanminh1975@gmail.com

Ngày nhận bài: 5.01.2021

Ngày phản biên khoa học: 25.2.2021

Ngày duyệt bài: 9.3.2021
}

Nguyễn Văn Tuấn ${ }^{1}$, Ngô Đức K Kaㄹ

đường typ 2 liên quan đến thời gian phát hiện bệnh $(p$ $=0,012)$, tăng huyết áp $(\mathrm{OR}=5,67 ; \mathrm{p}=0,04$; $\mathrm{CI} 95 \%: 1,65-19,46)$, vòng bunng tăng ( $\mathrm{OR}=5,67$; $\mathrm{p}=0,04$; CI95\%:0,05-0,61), nồng độ HDL-C $<0,9$ $\mathrm{mmol} / \mathrm{L}$ (OR=3,5; $\mathrm{p}=0,028$; CI95\%:1,11- 11,02), đường máu lúc đói $\geq 7 \mathrm{mmol} / \mathrm{L}(\mathrm{OR}=4,0 ; \mathrm{p}=0,017$; CI95\%: $1,24-12,89)$ và $\mathrm{HbA1C} \geq 7 \%(\mathrm{OR}=4,33$; $p=0,01 ; C I 95 \%: 1,39-13,56)$. Kết luận: Tỷ lệ MAU (+) ở bênh nhân đái tháo đường cao. Thời gian phát hiện bệnh đái tháo đường typ 2, vòng bụng tăng, tăng huyết áp, chỉ số $\mathrm{HDL}-\mathrm{C}$ giảm và kiếm soát đường máu kém là các yếu tố nguy cơ cho sự xuất hiện microalbumin niêu ở bênh nhân đái tháo đường typ 2 .

Từ khóa: MAU, đái tháo đường

\section{SUMMARY \\ MICROALBUMINURIA AND RELATED \\ FACTORS IN PATIENTS WITH DIABETES} MELLITUS TYPE 2

Diabetes mellitus is one of the most common diseases encountered in clinical practice. 